\title{
Call for papers
}

Call for Workshop Proposals to be co-located with the

5th International Conference on Intelligent Environments (IE'09)

http: / / intelligentenvironments .org/conferences / ie09/

IE'09 will be organized by the Technical University of Catalonia and held in Castelldelfels, Barcelona, Spain from July 19th to July 21st, 2009.

IE'09 will provide a leading edge forum for researchers and engineers from across the world to present their latest research and to discuss future directions in the area of Intelligent Environments.

The conference will bring together researchers from both industry and academia from the various disciplines contributing to the area on Intelligent Environments.

This coming edition is the next in a series of successful events that took place in the last four years: IE'05 (Colchester, UK), IE'06 (Athens, Greece), IE'07, (Ulm, Germany) and IE'08 (Seattle, USA).

The day before the conference takes place there will be a day completely devoted to host workshops on topics related to the main conference. These workshops can last for half day or for a whole day.

Topics of interest include, but are not limited to:

- Ambient Intelligence

- Ubiquitous Computing

- Pervasive Computing

- Intelligent Agents and Agent Technologies

- Middleware and Programming Models

- Context aware Systems

- Networking and Communications

- Human-Computer Interaction

- Multimodal Spoken Language Dialogue Systems

- Knowledge Management

- Domestic and Rehabilitation Robotic systems

- Smart sensors and actuators

- Smart Materials

- Architectural Aspects

- Art and Design

- Social Aspects

- Legal and Ethical Aspects

- Smart Environments Applications

- Virtual Environments

\section{Workshop acceptance rules}

Acceptance of workshops will be done through a two-stage process. Initially some of the workshops proposed will be selected based on the quality of the proposal and the topics covered. These workshops will later on be confirmed at the Final Selection Stage (see section "Important Dates") if they have successfully attracted a minimum of submissions and registrations to be considered at least as a half-day workshop.

\section{Financial support}

All workshops accepted at the Final Selection Stage will be financially supported by IE'09. This financial support will consist of: (a) waiving of workshop fees for a maximum of three co-chairs, and (b) the availability of a significant percentage of the registration fees attracted by the workshop to be used to pay expenses of hotel and/or travel for workshop co-chairs or keynote speakers.

\section{Bidding documents should include}

Title, details of organizers, general description of technical area, specific topics to be covered, proposed structure of the event, relevant experience of the organizers, other relevant information.

\section{Papers submission and publication of proceedings}

To be agreed after acceptance. 


\section{Conference organization and contacts}

\subsection{General chairs}

Dolors Royo

(Technical University of Catalonia, Spain)

Angélica Reyes

(Technical University of Catalonia, Spain)

Leandro Navarro

(Technical University of Catalonia, Spain)

\subsection{Programme chairs}

Achilles Kameas

(Hellenic Open University, Greece)

Vic Callaghan

(University of Essex, UK)

\subsection{Workshops chair}

Juan Carlos Augusto

(University of Ulster, UK)

jc.augusto@ulster.ac.uk

\section{Important dates for organization of workshops}

Reception of workshop proposals: 16th of March

Communication of initially selected workshops: 20th of March

Workshops receive papers from authors: 30th of April

Workshop organizers send IE'09 the structure of the proposed workshop: 29th of May

Early registration for conference and workshops: 6th of June, 2009

Final selection of workshops: 10th of June (based on number of papers accepted and registration numbers)

Workshop co-chairs send IE'09 final versions of accepted papers: 16th of June

Workshop day: 19th of July 